\title{
The association between febrile convulsion in children and chronic hyperventilation in parents
}

\author{
M Widiastuti Samekto, MD; I Gusti Putu Ardana, MD
}

\begin{abstract}
Background Febrile convulsion and chronic hyperventilation syndrome (spasmophilia) are suspected to share the same root of pathophysiology, a genetic trait abnormality related to ion channel that could cause neuronal hyperexcitability. We want to determine the prevalence ratio of parents with chronic hyperventilation syndrome between two groups of children with and without febrile convulsion.

Methods A cross-sectional design study was used, with a tertiary hospital setting (Kariadi Hospital). Participants were selected consecutively based on eligibility criteria. Febrile convulsion was diagnosed based on a modified Livingstone criteria. Chronic hyperventilation syndrome in parents was determined using the clinical diagnostic test of spasmophilia $(88.4 \%$ sensitivity and $61.6 \%$ specificity). Statistical calculations were conducted with two by two table analysis and within the 95\% confidence interval.

Results Sixty-two children (mean age 18 months) who met the eligibility criteria were included. The parents' mean ages were 33 years (father) and 29 years (mother). The prevalence ratio of father, mother and both parents with chronic hyperventilation between the febrile convulsion group and the non-febrile convulsion group were $2.56(95 \% \mathrm{Cl} 0.53 ; 12.31), 6.19(95 \% \mathrm{Cl} 1.70 ; 22.6)$ and 18.7 (95\% Cl 3.07;113.9), respectively.

Conclusion Febrile convulsion can be anticipated in children of parents who suffer from chronic hyperventilation syndrome [Paediatr Indones 2002;42:239-242].
\end{abstract}

Keywords: febrile convulsion, chronic hyperventilation syndrome

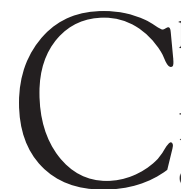

hronic hyperventilation (CHV) syndrome (also known as spasmophilia or neuronal hyperexcitablity syndrome) describes a set of somatic and psychological symptoms thought to result from episodic or chronic hyperventilation and usually are reproduced in whole or in part by voluntary hyperventilation. The syndrome consists of many symptoms, such as headache, fatigue, indigestion, paresthesia in extremities, cold and clammy hands and feet, anginalike chest pain, anxiety, and syncope. ${ }^{1-6}$ The incidence of this syndrome in the general population varies between $6-11 \%$ and may mimic diverse organic disorders. ${ }^{7}$ Steidle and Kalparek (1989) showed that people with spasmophilia had higher nervous excitability. ${ }^{8}$ This was also found in an unpublished data with odds ratio of 17.78 (95\% CI 2.18;144.83, $\mathrm{p}=0.001) .{ }^{9}$ The presence of gated ion channels in the plasma membranes of neurons gives these cells a property of electrical excitability. A genetic aberration that results in channelopathy, especially a voltagegated $\mathrm{Ca}$ channel, may underlie the increase of nervous excitability. ${ }^{10,11}$ Study on rats by Fan et al indicated that neurons in the caudal hypothalamus responsible for the modulation of respiratory output have a dominant T-type calcium current. This T-type current seems to have a role in the bursting characteristics of rhythmic firing in caudal hypothalamic neurons, thus resulting in abnormal respiratory drive. ${ }^{12}$

From the Department of Child Health, Medical School, University of Diponegoro, Indonesia.

Reprint requests to: Widiastuti Samekto, MD, Department of Child Health, Medical School, University of Diponegoro, Kariadi Hospital, Semarang 50231; Tel./Fax.: 62-24-311471 
Febrile convulsion (FC), a common form of childhood seizure, occurs in young children when there is a rapid increase in their body temperature. It affects about 1 in 20 children between the age of one and four but may affect those aged between six months and five year-old. Study by Racacho et al concluded that febrile convulsion has a genetic heterogeneity. ${ }^{13}$ Febrile seizures are frequently linked with epilepsy although the clinical and genetic relationships are poorly understood. Berkovic indicated that idiopathic epilepsies appear to be a family of ion channelopathies, either ligand-gated or voltage-gated, suspected to be the cause of abnormal neuronal hyperexcitability. ${ }^{14}$ Our hypothesis was that febrile convulsions and chronic hyperventilation syndrome may share the same pathophysiological root, namely a genetic abnormality related with ion channels which might be transferred. We tried to determine whether children with febrile convulsion have parents with a history of chronic hyperventilation syndrome.

\section{Methods}

\section{Study design and participants}

A cross-sectional study was conducted in 1999 with a tertiary hospital setting. Children with fever of more than $38^{\circ} \mathrm{C}$ and aged between 6 months and 4 years were selected consecutively among children who were admitted to Kariadi Hospital Semarang. Patients with sepsis and altered consciousness, brain infection, hydrocephalus, intracranial space occupying lesion, brain contusion, microcephaly, cerebral palsy, and developmental delay were excluded. Parents of children eligible for study were selected based on criteria: 1) "biological" parents; 2) both parents are still alive; 3) if parents were divorced, they are still accessible for questioning; 4) they agreed to be included in the study.

Parents with hypertension, stroke or post stroke, brain space occupying lesion, post severe concussion, heart disease or heart failure, peptic ulcer were excluded. If the parents did not meet the criteria mentioned above, the child was excluded from the study group.

\section{Determination of children with febrile convulsion}

Children eligible for study were screened for febrile convulsion. The diagnosis was based on the modified Livingstone criteria: 1) the first onset of convulsion was between 6 months and 4 years; 2 ) the duration of convulsion was less than 15 minutes; 3 ) the convulsion had the characteristics of a generalized seizure; 4) the onset of convulsion was during the first 16 hours of fever; 5) neurologic examination was normal before and after febrile convulsion attack; 6) EEG was normal one week after fever abated.

\section{Determination of parents with chronic hyperventilation syndrome}

The reference standard for chronic hyperventilation syndrome in the parents was EMG result after hyperventilation provocation test. Because of motivational constrain, instead of EMG evaluation, chronic hyperventilation syndrome was determined by clinical diagnostic test. The sensitivity of the test was $88.4 \%$ and the specificity was $61.6 \%$. Parents were regarded to have hyperventilation syndrome if they have a history of chronic syndrome consisting minimally one out of three somatic symptoms/signs (tension headache, cramps, moderate positive Chovstek's sign), and two out of three autonomic or visceral symptoms (paresthesia, cold and clammy hands and feet, indigestion, or chest pain).4,15

\section{Statistical analysis}

The characteristics of children with febrile convulsion and their parents were compared with the characteristics of children without febrile convulsion and their parents using t-test or chi-square test.

Two by two table analysis was used to calculate the prevalence ratio (included in the $95 \%$ confidence interval) of parents (either single or both) with chronic hyperventilation syndrome between the two groups of children.

\section{Results}

Sixty seven children were found eligible for this study; two were excluded because of developmental delay, 
M Widiastuti Samekto et al: The association between febrile convulsion and chronic hyperventilation in parents

one because of brain infection and two because of inaccessible divorced parents. There were no significant differences in demographic characteristics among the FC group (31 subjects) and the non-FC group (also 31 subjects) (Table 1 ). There was also no significant difference regarding the age of their parents.

Table 1. Characteristics of Study Group

\begin{tabular}{lll}
\hline Characteristic & $\begin{array}{c}\text { FC Group } \\
(\mathbf{n}=\mathbf{3 1})\end{array}$ & $\begin{array}{c}\text { Non FC Group } \\
(\mathbf{n}=\mathbf{3 1})\end{array}$ \\
\hline Age (months), mean (SD) & $18.77 \pm 9.52$ & $17.10 \pm 10.86$ \\
Sex (number) & & \\
$\quad$ Male & 18 & 19 \\
$\quad$ Female & 13 & 12 \\
Father's age (yrs), mean (SD) & $32.97 \pm 6.50$ & $32.74 \pm 6.15$ \\
Mother's (yrs), mean (SD) & $29.32 \pm 5.42$ & $28.68 \pm 4.73$ \\
\hline
\end{tabular}

If the percentages of father, mother or both with $\mathrm{CHV}$ among FC and non-FC group were compared, there were significant differences (Table 2).

Table 2. Proportion of parents With CHV in Each STUDY GROUP

\begin{tabular}{llll}
\hline CHV & $\begin{array}{l}\text { FC Group } \\
(\mathbf{n}=\mathbf{3 1})\end{array}$ & $\begin{array}{l}\text { Non-FC Group } \\
(\mathbf{n}=\mathbf{3 1})\end{array}$ & P value \\
\hline Father & 16 & 8 & 0.03 \\
Mother & 24 & 11 & 0.001 \\
Both & 11 & 5 & 0.00 \\
\hline
\end{tabular}

A separate two by two table analysis was conducted to calculate the prevalence ratio of father with $\mathrm{CHV}$, mother with $\mathrm{CHV}$, and both parents with $\mathrm{CHV}$ within the FC group and the non-FC group.

To calculate the prevalence ratio of father or mother with CHV within the FC group and the nonFC group, children with both parents experiencing CHV were excluded to prevent bias (Tables 3 and 4).

Table 3. Frequency of Father Within each study group

\begin{tabular}{lccc}
\hline & $\begin{array}{c}\text { FC Group } \\
\mathbf{n = 2 0}\end{array}$ & $\begin{array}{c}\text { Non-FC Group } \\
\mathbf{n = 2 6}\end{array}$ & $\begin{array}{c}\text { Total } \\
\mathbf{n}=\mathbf{4 6}\end{array}$ \\
\hline Father & & & \\
With CHV & 5 & 3 & 8 \\
Without CHV & 15 & 23 & 38 \\
\hline
\end{tabular}

Prevalence ratio: $2.56(95 \% \mathrm{Cl} 0.53 ; 12.31) \mathrm{p}=0.211$

The same way, to calculate the prevalence ratio of both parents with CHV within the FC group and the non-FC group, children with either father or mother experiencing $\mathrm{CHV}$ were excluded (Table 5).
Table 4. Frequency of mother in each study group

\begin{tabular}{lccc}
\hline & $\begin{array}{c}\text { FC Group } \\
\mathbf{n = 2 0}\end{array}$ & $\begin{array}{c}\text { Non-FC Group } \\
\mathbf{n = 2 6}\end{array}$ & $\begin{array}{c}\text { Total } \\
\mathbf{n}=\mathbf{4 6}\end{array}$ \\
\hline Mother & & & \\
$\quad$ With CHV & 13 & 6 & 19 \\
$\quad$ Without CHV & 7 & 20 & 27 \\
\hline Prevalence ratio & $6.19(95 \% \mathrm{Cl} 1.70 ; 22.6) \mathrm{p}=0.005$ &
\end{tabular}

Table 5. Frequency of parents in EACH StUdy GRoup

\begin{tabular}{lccc}
\hline & $\begin{array}{c}\text { FC Group } \\
\mathbf{n}=\mathbf{1 6}\end{array}$ & $\begin{array}{c}\text { Non-FC Group } \\
\mathbf{n}=\mathbf{1 9}\end{array}$ & $\begin{array}{c}\text { Total } \\
\mathbf{n}=\mathbf{3 5}\end{array}$ \\
\hline Both father/mother & & & \\
With CHV & 11 & 2 & 13 \\
Without CHV & 5 & 17 & 22 \\
\hline
\end{tabular}

Prevalence ratio $18.7(95 \% \mathrm{Cl} 3.07 ; 113.9) \mathrm{p}=0.001$

\section{Discussion}

Our study indicated that the prevalence of parents with CHV was significantly higher in children with febrile convulsion. If a single parent was involved, a mother with $\mathrm{CHV}$ was more prevalent than a father with CHV (prevalence ratio 6.19 compared with 2.56). This supports a previous study which demonstrated that women with CHV were more prevalent compared to men with CHV among outpatients of a tertiary hospital. ${ }^{15,16}$ The highest prevalence rate was found if both parents suffered from CHV (ratio 18.7). These facts support the idea that febrile convulsion and chronic hyperventilation syndrome may share the same genetic trait. This is also supported by reports describing pseudo-seizures in the absence of epilepsy caused by hyperventilation in children, suggesting that febrile convulsion and hyperventilation syndrome may have the same pathophysiology. ${ }^{14,17,18}$ Study by Han et al suggested that instability of breathing in chronic hyperventilation syndrome may be caused by genetic abnormal neuronal hyperexcitability. ${ }^{5,19}$

In conclusion, our study proved that for the majority, febrile convulsion can be anticipated in children of parents with chronic hyperventilation syndrome either from one or both parents. The results of our study might be useful for family education, guidance, and counseling. Even though successful effect of breathing therapy for chronic hyperventilation syndrome had been put forward by several researchers, would this be worth trying for children with the pro- 
pensity of febrile convulsion? We recommended further study concerning this issue, especially in older children since we can expect more compliance. 20,21

\section{References}

1. Delvaux M, Fontaine P, Bartsch P, Fontaine O. Tetany, spasmophilia, hyperventilation syndrome: theoretical and therapeutic synthesis. Rev Med Liege 1998;53:610-8.

2. Cristina S, Sandrini G, Ruiz L, Verri AP, Musicco M, Nappi G. A record card for the study of neuronal hyperexcitability syndrome. Funct Neurol 1996;11:53-8.

3. Lewis RA, Howell JB. Definition of the hyperventilation syndrome. Bull Eur Physiopathol Respir 1986;22:201-5.

4. Hornsveld HK, Garssen B, Dop MJ, van Spiegel PI, de Haes JC. Double-blind placebo controlled study of the hyperventilation provocation test and the validity of the hyperventilation syndrome. Lancet 1996;348:154-8.

5. Han JN, Stegen K, Schepers R, Van den Bergh O, Van de Woestijne KP. Subjective symptoms and breathing pattern at rest and following hyperventilation in anxiety and somatoform disorders. J Psychosom Res 1998;45:519-32.

6. Wheatly CE. Hyperventilation syndrome: a frequent cause of chest pain. Chest 1975;68:195-9.

7. Lachman A, Gielis O, Thys P, Lorimier P, Sergysels R. Hyperventilation syndrome: current advances. Rev Mal Respir 1992;9:277-85.

8. Steidle L, Kasparek J. Parameters of the M wave in 398 patients with tetanic syndrome proved with positive ischemic or hyperventilaton tests. Acta Univ Palacki Olomuc Fac Med 1989;123:237-52.

9. Widiastuti-Samekto. Spasmophilia and nervous excitability. Unpublished data 1993.

10. Lodish H, Baltimore D. Berk A molecular cell biology. $3^{\text {rd }}$ ed. New York: Scientific American Books; 1995. p. 949-67.
11. Tortora GJ, Grabowski SR. Principles of anatomy and physiology. $9^{\text {th }}$ ed. New York: John Wiley \& Sons Inc; 2000. p. 387-403.

12. Fan YP, Horn EM, Waldrop TG. Biophysical characterization of rat caudal hypothalamic neurons: calcium channel contribution to excitability. J Neurophysiol 2000;6:2896-903.

13. Racacho LJ, McLachlan RS, Ebers GC, Maher J, Bulman DE. Evidence favoring genetic heterogeneity for febrile convulsions. Epilepsia 2000;2:132-9.

14. Berkovic SF, Scheffer IE. Genetics of the epilepsies. Curr Opin Neurol 1999;12:177-82.

15. Widiastuti-Samekto. Diagnostic test of spasmophilia. Media Medika Indonesiana 1998;1(33):25-30.

16. Widiastuti-Samekto M, Alamsyah R. The Propensity to have tension headache in people with nerve hyperexcitability. Media Medika Indonesiana 2001; 2(36): 103-12.

17. Scheffer IE, Berkovic SF. Generalized epilepsy with febrile seizures plus. A genetic disorder with heterogeneous clinical phenotypes. Brain 1997; 120:479-90.

18. North KN, Ouvrier RA, Nugent M. Pseudoseizures caused by hyperventilation resembling absence epilepsy. J Child Neurol 1990;5:288-94.

19. Han JN, Stegen K, Simkens K Cauberghs M, Schepers $\mathrm{R}$, Van den Bergh $\mathrm{O}$, et al. Unsteadiness of breathing in patients with hyperventilation syndrome and anxiety disorders. Eur Respir J 1997;10:167-76.

20. DeGuire S, Gevirtz R, Hawkinson D, Dixon K. Breathing retraining: a three-year follow up study of treatment for hyperventilation syndrome and associated functional cardiac symptoms. Biofeedback Self Regul 1996;21:191-8.

21. Han JN, Stegen K, De Valck C, Clement J, Van de Woestijne KP. Influence of breathing therapy on complaints, anxiety and breathing pattern in patients with hyperventilation syndrome and anxiety disorders. J Psychosom Res 1996;41:481-93. 